Portland State University

PDXScholar

\title{
Effective? Ethical? Behavior Control \& Algorithmic Management in Virtual Environments
}

\author{
Ryan Moore \\ Portland State University
}

Follow this and additional works at: https://pdxscholar.library.pdx.edu/honorstheses

\section{Let us know how access to this document benefits you.}

\section{Recommended Citation}

Moore, Ryan, "Effective? Ethical? Behavior Control \& Algorithmic Management in Virtual Environments" (2018). University Honors Theses. Paper 633.

https://doi.org/10.15760/honors.648

This Thesis is brought to you for free and open access. It has been accepted for inclusion in University Honors Theses by an authorized administrator of PDXScholar. Please contact us if we can make this document more accessible: pdxscholar@pdx.edu. 


\title{
Effective? Ethical? \\ Behavior Control \& Algorithmic Management in Virtual Environments
}

\author{
by \\ Ryan Moore \\ An undergraduate honors thesis submitted in partial fulfillment of the \\ requirements for the degree of \\ Bachelor of Science \\ in \\ University Honors \\ and \\ Computer Science
}

Thesis Adviser

Ellie Harmon

Portland State University

2018 


\title{
Effective? Ethical?
}

\section{Behavior Control \& Algorithmic Management in Virtual Environments}

\author{
Ryan Moore \\ Department of Computer Science \\ Portland State University \\ ryamoore@pdx.edu
}

\begin{abstract}
As virtual platforms become more popular and grow larger the use of behavior control tools to aid in management becomes more common. In this paper I evaluate the effectiveness and ethicalness of behavior control tools, specifically the tools implemented by Uber and Upwork are assessed. These tools include "awareness systems" which are pieces of software that monitor work behavior with tools such as video recording and key logging. I create Frameworks for what is an ethical and what is an effective control tool and use them to evaluate both platforms. Next I do two Case studies on the platforms to show what behavior control mechanisms are used and how. Uber failed to meet a majority of both effective and ethical criteria standards. Upwork saw slightly better results reaching half of the effective criteria standards, but also did not meet a majority of the ethical criteria standards. Lastly I discuss ways to improve worker rights and privacy such as unionization and passing of laws and regulations.
\end{abstract}

\section{KEYWORDS}

Behavior control, awareness systems, algorithmic management, telecommuting, worker surveillance

\section{INTRODUCTION}

Working remotely with flexible hours and no supervisor watching over your shoulder has never been easier than it is today. Telecommuting is a common and growing practice, working remotely rose 79 percent between 2005 and 2012 and as of 2017 telecommuter's makeup 2.6 percent of the American work force, or 3.2 million total workers [1]. Platform work has contributed to this growth, with popular applications including ride sharing and freelancing. Platform work or 'app-based' work includes any kind of work that is done virtually and workers are managed through the platform. Virtual environments such as these allow for the quick formation of teams that rely on non-face-to-face forms of communication, meaning workers, team members, and managers often do not physically meet. This new type of working environment comes with new types of problems. One such issue that arises on virtual platforms is performance, or rather tracking of performance. If an employer does not see what a worker is doing, how can they know the worker is getting the job done? Performance management is by far the biggest challenge on virtual environments [2] and generally adopted managerial practices are not well suited for virtual environments [3]. Different managing techniques are needed to organize this new type of labor and many tools have been created to help bridge the gap, such as awareness systems, work diaries, and crowdsourced rating systems. In this paper, I examine the behavior control mechanisms that are now widely used by online platforms to exercise authority or to influence workers behavior [3]. These mechanisms include thigs such as applications installed on work phones that track worker location, tools that log screenshots or web camera captures of workers, and keyword notifications on work emails and work phones. While behavior control mechanisms are made to help improve worker effectiveness, they also raise privacy and other ethical issues.

Modern surveillance tools have seen recent and drastic changes, crossing the boundary of enhancing performance to breaching privacy. Surveillance can occur in not just the workplace, but also outside of it, bleeding into people's personal lives [1]. In 2015 a woman was fired for uninstalling an application on her work provided phone that tracked her location at all times, even when she was off work [4]. Tracking work phones, installing keyloggers, and examining browser history are just a few of the ways a worker can be monitored when nobody is around them. Close supervision that was previously done by middle management is much easier and can even be automated through awareness tools. If a manager was working on a virtual platform, with workers distributed all around the world, what would be the simplest way to guarantee workers are optimally performing?

Studies on labor and trust in virtual teams have been done across multiple fields. However, these studies look at the issues from very specific and different angles. Business research shows how to use monitoring to increase performance, labor research discusses how worker privacy is being invaded and current laws are not protective enough, others investigate how surveillance affects team members trust in each other and their employer. Labor changes in virtual environments is still a young topic and has not been mapped out well yet. There are no federal laws that expressly address employer surveillance or limit the intrusiveness of such surveillance [1]. This topic is important for laborers everywhere, as technology is 
allowing the workforce to change, but laws and regulations do not appear to be keeping up. By combining these different discourse communities this paper hopes to give a better understanding of the many issues present in virtual teams and that the systems being used on these teams have effects past what they were intended for. In this paper I create frameworks for assessing both the ethicalness and effectiveness of a companies use of behavior control tools. To generate the frameworks, I draw on research that has been conducted on specific platform environments, general virtual teams, as well as the ACM code of ethics. I carefully examine two virtual work platforms - Uber and Upwork - and their use of behavior control mechanisms, which I evaluate using the ethical and effective frameworks. To conclude, I discuss the evaluations of both platforms and speculate on the future of behavior control tools in the workplace. Specifically, how Uber and Upwork both fail to meet a majority of all criteria, and how their lack of transparency, over collection of data, and worker classification hold the two platforms back from meeting criteria. When discussing how to improve the future of behavior control tools I look at both union and new laws/regulations.

\section{METHODS}

In this paper I take a case study-based approach to analyze the degree in which behavior management tools used in platform work are ethical and effective. The goals of this research are to examine the impact decisions made by algorithmic management systems has on workers, evaluate the effectiveness and ethicalness using behavior control mechanisms has on laborer's in virtual environments, and to find real evidence that either supports or does not support if these systems and tools are effective and/or ethical in the specified platforms.

The two cases I chose are Uber and Upwork. I chose these two platforms because they illustrate how the modern workforce is changing. Technology allows for forms of labor that were previously not possible on this scale. Ridesharing applications and telecommuters are two prime examples of technology creating new industries. Uber is the largest and by far the most popular ridesharing service [5]. Its popularity and rapid growth show not only that ridesharing application industry is a success, but also that similar industries can be as well. Upwork is the most popular platform for telecommuting freelancers today [6]. In the United States telecommuter's makeup 3.2 percent of the workforce, with the largest growth in the workforce since 2008 coming in 2018 [7]. The recent growth of both these industries gives us insight into the future of the workforce. My evaluation of both platforms is based on two extensive literature reviews.

The first literature review focused on identifying what is known about worker control, productivity, and ethical technology use. For this review I started by separating examined literature into two different categories: what makes for ethical behavior control tool use and what makes for effective use. Aided by this extensive list of sources I then created two separate frameworks for determining what is ethical and what is effective when behavior control tools are used on virtual platforms.

The framework for evaluating the ethicalness of behavior control tools uses sources that discuss ethical management and ethical monitoring, but is most heavily based on the ACM code of ethics. The Association for Computing Machinery is the world's largest educational and scientific society for computing [8]. It was founded in 1947 with the goal of advancing the art of computing, in part, by promoting the highest professional and ethical standards [9]. They created multiple codes of ethics, for members, software engineers, and committee members. Thus, the ACM code of ethics will be used as the frameworks foundation for what is ethical in virtual environments. I researched how behavior control tools allow for ethical violations finding three major points of ethical conflict: data, transparency, and quality of life. I then looked at these factors through the lenses of the ACM codes of ethics. I selected specific criteria that had potential to violate the codes and fell within the scope of the three main factors.

The framework for effective use of behavior control tools uses sources from a variety of areas. I reviewed literature on worker control and productivity in different environments from the fields of information systems, computer supported cooperative work (CSCW), communication studies, human-computer interaction (HCI), and business management. These areas of research each explore behavior control tools through different lenses but bring up similar points of interest. Across the sources I identified seven key criteria that repeatedly influenced the effectiveness of work. After identifying all seven influencers I examined how each of them could be influenced by behavior control tools to positively or negatively affect worker productivity and quality.

The second literature review focused on gathering accounts of technologies and practices found in Uber and Upwork. For this review I used recent publications reporting on research into the experience of workers on both platforms. I began by examining the type of work both companies do and how they create such rapid growth. I follow this initial research by looking into the worker classifications of both platforms users, as it appeared to influence use of behavior control tools in both. After clarifying the companyworker relationship I used both primary and secondary sources to discover and examine the behavior control tools used by each platform. I used articles from reputable popular media outlets that give accounts on the use of behavior control tools by Uber and Upwork. After examining the two platforms are I evaluate their use of behavior control tools for ethicalness and effectiveness by using the frameworks created in the first literature review.

\section{DEFINITION OF CORE QUESTIONS}

The framework for assessing the ethicalness of a platforms use of behavior control tools compromises 7 key criteria. These criteria allow for the assessment of the ethical nature of a surveillance system in terms of data collection, the effects of behavior control on working conditions, and the transparency and regularity with which tools are used.

\section{Ethical}

Using behavior control that surveil workers behavior can quickly lead to the crossing of ethical lines. But what are these lines? What does it mean for a work provider that uses a virtual platform to be 
ethical? These questions do not have simple answers, as there are many different aspects to an ethical virtual workplace, compared to the standard workplace. Specifically, virtual platforms that use algorithmic management and standard managerial practices do not work well together [3]. New tools and techniques have been created and used, come that have the potential to be used for ethically questionable purposes. To determine if behavior control mechanisms used by specific platforms are ethical, I create a framework relying heavily on the ACM code of ethics.

\section{Criteria for Ethical Behavior Control}

There are seven total criteria for ethical use of behavior control tools by a virtual platform. For a platform to be ethical all or a large majority of the below ethical statements must be true.

1. Only necessary data is gathered.

2. Gathered data remains confidential, its integrity is maintained, and is correctly available.

3. Gathered data is accurate.

4. The tools used enhance working life quality.

5. The tools used do not discriminate against specific groups of workers.

6. Workers are aware of how and when they are being monitored/influenced.

7. Work providers provide and uphold clear policies on surveillance and control tools.

1. Only necessary data is gathered

This criterion is supported by section 1.7 of the ACM code, "respect the privacy of others". One of the implications of this is that only the necessary amount of personal data should be gathered [10]. Since personal information can be gathered at a rate that is larger than ever seen before, the potential to violate privacy is hugely increased [10]. There are multiple behavior control tools with the potential to gather unnecessary data. For instance, awareness systems that track workers when they are off the clock, information that is not needed by work providers.

2. Gathered data remains confidential, its integrity is maintained, and is correctly available

The ACM code of ethics section 1.8 states "Honor confidentiality" [10]. Gathered data, including potentially private worker data should remain confidential, meaning measures are taken to prevent that information from being accessed by the wrong people. It should only be available to those who need it. Also, the integrity of the data must be maintained so that its accuracy is preserved. These three characteristics (confidentiality, integrity, and availability) form the triad of information security [11]. Meeting the three characteristics is important for the security of any organizations information [11].

\section{Gathered data is accurate}

Similar to the first criterion of this list, accuracy of data is supported by section 1.7 of the ACM code - "respect the privacy of others". As modern society allows for an increased risk of violating privacy, it is up to the professionals who gather data to ensure its accuracy [10]. Algorithmic management relies heavily on gathered data to make decisions, behavior control mechanisms such as push notifications or work assignments are data driven. The accuracy of data is imperative to workers on virtual platforms who use algorithmic management, as incorrect data leads to incorrect decisions from data-driven algorithms.

\section{The tools used enhance working life quality}

The ACM code of ethics section 3.2 states that "organizations should design and build information systems that enhance the quality of working life" [10]. New technology should be made to improve life, specifically for workers who use it, not degrade working life. Control tools that use worker monitoring have the potential to create a more hostile workplace, for instance, intrateam surveillance increasing the salience of accidents [12].

5. The tools used do not discriminate against specific groups of workers

The ACM code of ethics section 1.4 states "Be fair and take action not to discriminate" [10]. Workers of a specific group should not experience more behavior control than others. Discrimination in distributed teams is just as, if not more relevant than in the standard workplace as virtual teams are more likely than face to face teams to be demographically diverse [13].

6. Workers are aware of how and when they are being monitored/influenced

The ACM code of ethics section 2.5 states "Give comprehensive and thorough evaluations of computer systems and their impacts, including analysis of possible risks" [10]. Awareness systems gather a lot of data that many deem to be private information. Therefore, workers should understand how the monitoring system works, to better understand its capabilities [12], so that they may protect themselves from the risks associated with the gathering of potentially private data.

7. Work providers provide and uphold clear policies on surveillance and control tools

The ACM code of ethics section 2.6 states "Honor contracts, agreements, and assigned responsibilities" [10]. Policies should be provided to workers in a way they understand, so they can understand how, when, and why they are being monitored. Work providers should have clear policies on surveillance for workers and distribute them over official channels [14]. These policies allow for proper disciplinary plans to be upheld and workers to ensure their work provider is being responsible and reasonable [12].

\section{Influencers of Effective Behavior Control}

The nature of these behavior control mechanisms is to reward compliance with existing rules and worker uniformity [3]. These tools influence behavior in ways that are intended to benefit the overall workflow. However, many tools have unintended consequences that instead hinder the workflow. There are many facets of worker effectiveness that should be considered when attempting to increase said worker effectiveness. Research into behavior control and worker surveillance revealed specific repeated aspects that influence worker effectiveness.

The framework for assessing the effectiveness of a platforms use of behavior control tools also comprises 7 key criteria. These criteria allow us to assess the effectiveness of awareness systems to build team trust with communication or to violate an individual's privacy, the effects of behavior control tools that keep workers on task with reward systems, and algorithmic managements use of feedback as well as its capabilities of retaining workers. 
1. Trust

2. Communication

3. Worker focus/on-task

4. Reward/Payment structure

5. Feedback

6. Worker experience

7. Privacy

Each of these influencers can both increase or decrease worker effectiveness and has a specific relation to behavior control mechanisms. They will be individually examined to show their importance to effective work / behavior control.

\section{Trust}

Trust was the most common theme found in research relating to worker performance in virtual environments. Specifically, how awareness systems influence trust in teams of telecommuting workers. In fact, the effects of behavior control tools on trust and performance of virtual teams is heavily dependent on worker monitoring [15]. External monitoring of teams increases trust by reducing ambiguity and conflicts. Virtual teams that used internal monitoring showed a strong positive relationship between affective trust and performance [15]. These tools also have potential to drastically decrease trust in team environments, for instance, internal monitoring by increasing the salience of accidents [15] The gap of trust between those who tend to deem others as trustworthy and those who do not is widened by behavior control mechanisms [16]. Whether or not awareness systems help or hurt trust depends on who does the monitoring, as well as the type of trust [17].

\section{Communication}

To virtual teams and workers on virtual platforms, communication is incredibly important. In many of these work environments laborer's never meet face to face, instead interacting entirely through other methods. Awareness systems are often offered to virtual teams as a way to provide contextual information and promote trust [17]. Being able to watch a team members work allows for a form of indirect communication, helping team members provide a context to their work. Teams that share more information tend to see higher levels of performance [2].

\section{Worker focus/on-task}

Perhaps the most important reason for work providers to use behavior control tools is to ensure workers stay on task.. Recording a person as off task when they are simply not typing, which does not necessarily indicate they are off-task [12]. Quickly leading to incorrect measurements of performance. However, in the digital age wasting time with "cyber lollygagging" is not a small problem, ensuring workers are productive is necessary for a company's success [14].

\section{Reward/Payment structure}

Having an accurate reward structure is closely related to keeping workers on task. Whether or not workers are working hard requires proper measurement. Behavior control mechanisms often lead towards worker uniformity, meaning workers are productive in the way the system wants them to be. When they could be more productive in their own way. For instance, virtual platforms that pay by the hour can place high productivity workers at a disadvantage, as they get tasks done quicker [16]. However, if the reward structure supports different types of workers, productivity can be more accurately rewarded.

\section{Feedback}

Worker feedback that is normally given by a supervisor or manager is commonly automated in algorithmic management. Systems use feedback as a form of behavior control, to influence workers to act in a certain way, which is a form of emotional labor [19]. This behavior controlling feedback influences workers to work in a way that benefits the platform. However, the reduction of management personal also causes a lack of capability to respond personally to workers. Platforms are not always able to properly manage all of their workers, for instance many platforms resort to interacting with workers through pre-made template responses [19].

\section{Worker experience}

Better performance, work quality, and loyalty are the benefits mainly gained from a worker with experience [20]. Experienced workers are clearly valuable, but behavior control mechanisms often influence workers to leave, some platforms see high turnover rates [21]. The issue being that virtual platform models can be to biased towards the work providers requirements [20]. On the other side, awareness systems help team members gain context of their situation, allowing them to gain experience not just through their own mistakes but their team members as well [2].

\section{Privacy}

Worker privacy has a surprising effect on effectiveness, specifically on productivity. Decreasing worker observation can increase productivity and slow productivity when workers know they are being observed [22]. What work providers see when they are monitoring workers is somewhat of a performance, workers will do just what they are expected to do. When monitoring is expanded workers resort to more subtleness, strategically hiding behavior and encrypting it to reduce understanding of what is seen [22]. Awareness systems that constantly watch lead to more complicated ways of circumventing being watched, which may have a negative effect on productivity as increasing amounts of worker energy and attention become devoted to system circumvention.

\section{CASE STUDIES}

Now that I have outlined the two frameworks, I present some background on each of the 2 platforms I examine in this paper, and describe the kinds of behavior control and monitoring tools found on each one.

\section{Uber}

Ridesharing applications have been gaining traction for years and are only getting more popular. From 2014 to 2015 the number of Uber drivers more than doubled, from 160,000 to 400,000 [19]. At the end of 2017 Uber had two million drivers and was valued at 70 billion dollars [23]. For such a massive company, maintenance through client interactions with a mobile application is complicated. The application does not just manage ride allocation, 
but it also processes payments, tracks distance, sets fare rates, and acts as a medium for the company and drivers to communicate [24]. This huge structure is enabled by delegating managerial tasks normally done with human supervision to the platform [25], [21]. Uber has produced a form of on-demand labor that is managed, compensated, and allocated, all from the application [24].

Uber and other similar applications are part of the newly emerging 'sharing economy' where consumerism around shared goods and activities rival private consumption whilst providing low benefits and insecure work [24]. The lack of security and benefits provided by jobs in the sharing economy raises an obvious question, why work for these companies? Uber attracts drivers by stating workers have the chance to be their own boss, work whenever they want to and wherever they want to [25]. This promise of flexible employment attracts many drivers, in a survey $85 \%$ of respondents said it was a major motivation for starting [19]. These claims of flexibility and being one's own boss are not always experienced in practice, primarily due to the information/power asymmetries between drivers and the platform, algorithmic task assignment/management, and the emotional labor driver's must perform [25]. However, many drivers view the flexibility and choices that they do have compensate for their lack of control in matters dealt with by algorithmic assignment [21].

Working under Uber's algorithmic management is not as straightforward as most jobs. Officially, drivers are not Uber employees, they are called "driver-partners" and are independent contractors $[19,25]$. Uber claims to be a technology company that does not provide transportation services, but instead offers a platform on which these services can be arranged. Thus, a driver's in-person contact with Uber staff is limited, if anything, to just the recruitment process. The rest is handled by the platform. Numerous channels filter data from drivers to Uber, but paths for drivers to get information from Uber are limited to decentralized support centers where Uber employees act more as customer service representatives than managers [19]. The structure of information available for drivers through the platform is often at odds with the goals of the driver. Drivers constantly must calculate the costbenefit of rides, without the support of Uber [25]. Issues like these are partially why retention rates are so low; only slightly over half the drivers who on-boarded in 2013 remained active a year later [19]. Workers that remain on this platform find that the temporal demand of riders and working on their own time do not always go hand in hand [26]. Drivers can have flexible hours unlike the fixed schedule many taxi drivers see, but rides are not always available outside of set times. Uber drivers on average make more hourly than taxi drivers, work fewer hours, and experience a more social environment [24]. These perks over taxi drivers that partially come from flexible hours are dependent on demand and base rates. However, the choices Uber promotes to its workers mask what could easily be defined as a managed workforce [19].

The decentralized structure of Uber and the freedom users experience give the impression that Uber has a limited managerial role over drivers, which supports their claim that drivers are not employees [19]. However, constructing a platform like Uber is in many ways a managerial act [25]. The platform uses gathered information and power asymmetries to apply conditions of soft control, affective labor, and gamified patterns of worker engagement on drivers [19]. This algorithmic management complicates the claim that Uber only operates as an intermediary as they have the power to incentivize, homogenize, and generally control how workers behave [19]. The supply-demand algorithms Uber uses were originally designed for mathematical optimization, not for human management. These algorithms do not consider the pace at which human's work [21]. They control and manage drivers, instead of serving as a tool that drivers can leverage to help make decisions [25]. As managerial decisions are made in the background, the involved parties are left trying to figure why the algorithm did what it did, so they may adjust their own behavior accordingly [26]. There are 3 main behavior control tools Uber uses to influence the relationship between supply and demand: driver assignment, dynamic surge pricing, and data driven evaluations (ratings). These respectively relate to the decisional, informational, and evaluation roles of a human manager [21].

Uber claims to assign rides based on driver proximity to passengers. The pay rate for these rides is either a fixed rate or influenced by the dynamic surge pricing algorithm. Drivers can choose to accept a ride, but how the assignment is presented influences worker cooperation with it [13]. Drivers also have an acceptance rate cut off which encourages them to accept as many assignments as possible [21]. Drivers work is also heavily influenced through surge pricing and notifications. With surge pricing Uber can generate and coordinate response to a dynamic market demand [19]. Notifications during surge pricing can either urge drivers to begin driving or urge drivers to work more [19]. Surge pricing algorithms directly influence driver behavior; however, the pricing is often not reliable for drivers [19], [21]. In response to the unreliability of surge pricing an Uber spokesperson said "We are not setting the price. The market is setting the price. We have algorithms to determine what the market is" [19].

The evaluation role of managers for Uber has been passed to the rating system. On Uber's platform drivers are rated between 1 and 5 , having to keep their average rating above a certain threshold to remain with Uber. This acts as a form of surveillance and performance rating on drivers, forcing them to adapt to customers social and emotional needs, adding a form of emotional labor to the driver's responsibilities [24]. Drivers and Uber emphasize the importance of building a good relationship with passengers [26]. This rating system empowers passengers to act as middle managers over drivers [19], effectively crowdsourcing control and supervision of drivers [25]. However, most passengers do not understand how the rating system works [26]. Drivers are aware of this, 45 percent of respondents in a survey agreed the rating system does a poor job of promoting trust between passengers and drivers [26]. Uber will send out routine messages that recommend specific ways to act to get high ratings, and actions that will get low ratings [19]. The feedback is carefully designed to be indirect, as to avoid appearing as company policy [19]. This business model is rooted in Taylorist traditions of using worker monitoring to create more efficient workflows [19]. As this work is intermediated electronically, monitoring is passive, making control less perceptible.

Worker monitoring is a tool Uber uses frequently, but not one that has gone by unnoticed. Their secret tracking technology is one of the reasons the companies license was denied renewal by the city of London [27]. The company is known to push boundaries on user tracking, they eliminated an IOS setting that allowed users to only 
be tracked when using the application [28]. Driver and passenger locations can be tracked non-anonymously using a tool Uber calls "godview" [28]. They have tracked phones of police and government officials they deemed to be violating the terms of service by disrupting operations with a tool called "greyball" [28], [29]. Another tool known inside of the company as "Hell" was used to track the location of drivers for Lyft, Ubers main competitor [30]. Uber has tracked users when the application is not on, nonanonymously tracked its drivers for others to see, tracked and denied service to government officials, and tracked drivers of competing companies.

Driver monitoring and tracking is done for more than just ride assignment and behavior control. By collecting GPS, gyroscope, and accelerometer data from drivers and customers Uber creates driving habit reports for drivers [31]. This data is used to find helpful information like: rapid acceleration, hard braking, speeding, and location specific trends [31]. These statistics make it possible for Uber to influence their drivers towards safer habits. Collected information is stored on long term servers at Uber where it aids in the building of autonomous vehicles [31].

Uber has many tools available to influence the behavior of its users and face little regulation when it comes to how these tools influence workers.

\section{Upwork}

Upwork's predecessor, Odesk was a website founded in 2004 as an online labor market where laborer's and providers can coordinate work in real time. Both providers and workers agree on a payment rate and process all payments through the platform, where a 10 percent fee is charged [18]. Both freelancers and work providers were attracted to the platform, oDesk partnered with large companies such as Yahoo, Facebook and Sun Microsystems [18]. Perhaps the biggest reason oDesk attracted a large number of freelancers is that it accessed a global pool, allowing for the creation of decentralized task-based teams of workers. ODesk provided the needed tools for project managers to mobilize workers in over 50 countries [18]. In 2015 oDesk merged with its biggest competitor to create an even larger company, Upwork [32]. By 2017 Upwork hosted 9.3 million freelancers and 3.7 million employers in 180 countries [33]. However, this increase of laborers changed work on the platform. Freelancers faced new demands and had to adapt, the work began to resemble microwork instead of creative positions and fewer found work whilst a few earned a lot [33]. On average a freelancer on Upwork worked with 22 providers and repeated work with roughly 18 percent of those providers [32]. Worker success on the platform and others like it depends on more than just expertise and connections, but also mastering the platform and receiving high ratings.

Upwork is able to attract workers with a number of good looking statements. The most important two being freedom and payment. They stress that each year their freelancers earn over $\$ 1$ billion in a workplace that is personally and professionally rewarding for anyone with the proper skill set and a reliable internet connection [33]. In a survey of workers on the platform 47.3 percent of respondents stated Upwork is their primary source of income [18]. These workers managed to find some sort of sustainable income from the platform. The same survey found being able to work from home as another major advantage [18]. Upwork emphasizes the flexibility of being able to work from wherever they want however they want to gain new workers [33]. However, with globalization came workers willing to work for lower rates; as of 2017 the US was Upwork's top employer whilst India was its highest earner [33].

Upwork follows a similar worker model as Uber, were it does not view itself as an employer of the users of its platform. Upwork is not a labor service company, but a technology company that provides the creation and maintenance of an online marketplace [18]. To join the platform users must agree to the user agreement. This agreement states that Upwork is just a venue and that users are not affiliated with the company, any work agreement is between the worker and the provider [18,33]. The creative freelancer narrative of work that is maintained by Upwork distances the platform from the risks that are inherent to an employment marketplace by downplaying the role it plays [33]. Despite their claims to be an intermediary, Upwork does play a role in controlling workers through its monitoring and rating systems.

Upwork's most distinctive and most controversial tool is its monitoring system [34]. The surveillance tool known as Team Application has been referred to by some as " 21 st century big brotherism" [18]. This application takes screenshots every ten minutes, monitors keystrokes and mouse clicks, and even allows webcam captures [33]. The Team Application was the platforms answer to what the previous CEO Gary Swart said was their biggest hurdle - helping companies monitor work [18]. Work providers have a work diary submitted to them with the completion of a project, it contains the data gathered by Team App as well as notes and a time log from the worker [33]. When working on a team or with multiple providers, all team members can view each other's work diary [18]. Payment is guaranteed as long as workers are logged into the application, which roughly 85 percent of freelancers spend at least one hour on per week [18]. Should a worker choose to review their diary and not submit a screenshot, they forfeit 10 minutes of work $[18,33]$.

Online marketplaces generally have a feedback and review system to create some sort of reputation score, which affects the decisionmaking process of hiring for work providers [32]. Before becoming Upwork, oDesk implemented a two-way feedback system with criteria such as productivity, quality of work, and collaboration [18]. That creation remains in Upwork and now this reputation fuels the marketplace, as the gathered data is aggregated into a job success score [33]. A worker's chances of being hired is substantially increased by this rating algorithm, whose exact criteria is not disclosed [32]. The platform allows providers to quickly shift through workers looking at their scores when hiring [34]. Providers tend to prefer candidates that they consider more credible by having a coherent career trajectory, workers that move between different job types or fields are less likely to be selected [32]. For instance, an irregularity in a career pattern such as a maternity leave will penalize a worker [32]. These algorithm-based rating systems are intended to build a social trust [32], but they also punish any non-uniformity seen in a worker.

Workers on the platform have mixed responses to these control mechanisms. Over 44 percent of workers found the surveillance to 
be intrusive, but others felt that it was necessary to establish trust or were just willing to forgo their privacy for a guaranteed payment [18]. Despite how workers felt about the intrusiveness of the monitoring, a majority (50\%) of workers thought that it made them more productive and only $7 \%$ said it made them less productive [18]. However, being on task does not guarantee increased performance. Some workers felt that hourly work at a slower place was rewarded, putting high productivity workers at a disadvantage [18]. As far as building trust between both parties goes, the time monitoring that is the most valuable is when a new relationship is being built, not when one is already established.

Upwork sees the transparency offered by these control mechanisms as one of the primary reasons for the platforms popularity and competitiveness [18]. Many companies have attempted to use similar tools to connect workers, but Upwork is the most successful of these platforms [33]. The monitoring tools provided by Upwork allow work providers to guarantee work with virtual time clocks and imitation supervision [35]. The rating system increases the efficiency in freelancer-provider matching, which attracts work providers with saved time [33]. Upwork argues these tools provide some measure of security for work providers and foster trust between the two parties, as both sides have given their consent to the terms of use [18].

\section{EVALUATION OF ETHICS}

In this section I look at each criterion for ethical use of behavior control tools in both platforms. I determine whether each platform is either ethical or unethical based on how the specific platform uses its control tools. I find Uber to use behavior control mechanisms extremely unethically. Upwork is found to be only somewhat unethical. The difference between the two is caused by the lack of transparency on Ubers platform. Both suffer from their surveillance tools invading worker privacy.

\section{Uber}

Uber failed to meet 6 of the 7 criteria for ethical use of behavior control tools. Thus, I must label Ubers use of said tools to be unethical. Gathering data with tools such as "Greyball" and "Godview", as well as an overall lack of transparency hold the company back from achieving ethical use of behavior control tools.

1. Only necessary data is gathered.

Uber requires a large amount of data for its algorithmic management to run well, as it is data driven. Much of this data is needed for maintaining the quality of the driver user relationship, calculating surge pricing, and proper driver assignment. However, Uber has tracked the location of users when the application is closed, removed the iOS setting to disallow tracking when the application is closed, and used the tool they named "Godview" to non-anonymously track drivers [28]. Uber unethically gathers unnecessary data.

\section{Gathered data remains confidential, its integrity is} maintained, and is correctly available.

In the past Uber has not upheld proper data confidentiality for their drivers. The "Godview" tool can be used for the non-anonymous tracking and displaying of driver locations [28]. By displaying nonanonymous driver locations in insecure settings Uber has failed to keep private driver data secure and confidential.

\section{Gathered data is accurate.}

Uber's rating system is an important behavior control tool for the platform, but it does not provide accurate data. The system is crowdsourced to passengers [25], of which a majority do not understand how it works [27]. Uber unethically gathers inaccurate data by collecting incorrect evaluations of its drivers.

4. The tools used enhance working life quality.

Uber's use or a rating system to replace middle management may be necessary to maintain their driving fleet. However, as a majority of passengers do not understand how the rating system works [26], a form of emotional labor is forced upon drivers [24]. Uber takes advantage of this emotional labor to control driver behavior [19], making this rating system a tool that does not enhance the quality of working life and therefore is unethical by this criterion.

\section{The tools used do not discriminate against specific groups of} workers.

The use of the "Greyball" tool by Uber may prevent government officials from riding, but it is used on riders, not on drivers. As this tool does not implement a form of behavior control on a specific group of drivers, it does not violate ethical concerns on Uber's laborer's. There are many arguments that can be made for the unethical nature of this tool, but it does not violate this specific criterion.

\section{Workers are aware of how and when they are being monitored/influenced.}

As previously stated in section 1, Uber has tracked the location of users on its application when the application is closed [28], which violates this principle because workers did not know that they were being monitored all the time. The company's use of indirect messages in notifications to maintain their driver's employment status [19] also potentially violates this principle. By masking messages on improving ratings as suggestions, worker understanding of this influence can be lost, as they are unsure of the importance of this indirect message. Uber unethically monitors and influences its workers when they are not aware and in ways they do not understand.

\section{Work providers provide and uphold clear policies on surveillance and control tools.}

Due to the employment status of Uber's drivers, some of the implemented behavior control mechanisms are indirect. When feedback on improving rating is given to drivers by Uber, it is carefully crafted so that it cannot be viewed as company policy [19]. By attempting to control driver behavior outside of the bounds of company policy, Uber fails to ethically provide clear policies to their drivers. 


\section{Upwork}

Upwork saw better ethical results than Uber, with only 4 out 7 criteria failing to be met. The behavior control tools implemented by Upwork are only partially unethical. The team application implemented by Upwork is invasive, but the platform manages to keep itself from being extremely unethical through clear policies and allowing workers to access their work diaries. The rating system used is not as clear, therefore holding the platform back from a more ethical evaluation.

1. Only necessary data is gathered.

The team application tool gathers far more data than what is necessary. It takes screenshots, records keystrokes, and even allows for use of webcams [33]. Much of this data is not necessary for Upwork, nor for work providers on the platform. As Upwork is a telecommuter platform, these workers will be using their own devices. Upwork uses the team application tool to unethically gather an unnecessary amount of data.

\section{Gathered data remains confidential, its integrity is} maintained, and is correctly available.

The team application may gather an unnecessary amount of data, but its confidentiality is clear, integrity can be checked by the worker, and the data is properly available to those that need it. The data gathered is placed in a worker diary that the worker can go through and remove information from [33]. This data is available to team members and work providers [18]. Since the worker is aware of who can access their diary this ethical principle is not violated.

\section{Gathered data is accurate.}

As stated above, workers can access their work diary, meaning that workers can ensure the accuracy of gathered data themselves. Allowing workers the option to protect themselves from inaccurate data prevents Upwork from violating this principle.

4. The tools used enhance working life quality.

The monitoring done by the Team Application tool does not improve or enhance the quality of work life. A majority of users found its surveillance to be intrusive [18]. The laborer's who require the income from this platform will, in many cases, have to use this tool. Upwork unethically uses tools that directly degrade the quality of working life.

5. The tools used do not discriminate against specific groups of workers.

The rating/feedback system implemented by Upwork is extremely influential on work providers hiring workers [32]. Providers want laborer's that the platform says do good work. Where this becomes unethical is the algorithms weighted use of uniformity. Workers that deviate from a uniform career path can be penalized, which affects workers who have periods of time they cannot work [32]. This platform provided rating system has the potential to unethically influence the hiring of workers, who may experience career irregularities due to their health, for example, maternity leaves.
6. Workers are aware of how and when they are being monitored/influenced.

The Team Application provided by Upwork may have multiple unethical aspects, however is it clear to workers when they are being monitored and how. To use the application workers have to $\log$ into it [18]. This tool acts as a surveillance mechanism and a punch card. Since workers can login and logoff as they please and the application truly closes when they are logged off, no ethical violation is made in the context of this principle

7. Work providers provide and uphold clear policies on surveillance and control tools.

Upwork's Team Application does have clear policies, but its rating tool does not. Workers are influenced to receive good ratings by the platforms hiring algorithm, but its criteria for hiring are not disclosed [32]. The importance of feedback and ratings in online work platforms creates a large behavior control aspect, which Upwork unethically uses by not disclosing the aspects by which it scores workers.

\section{EVALUATION OF EFFECTIVENESS}

In this section I look at each criterion for the effective use of behavior control tools on both platforms. Each platforms behavior control tools are determined to be either effective or not effective based on whether the control tools uphold or violate each criterion. Both platforms are found to use behavior control mechanisms somewhat effectively. Uber suffered from its worker classification, making all types of communication difficult, as direct communication and management is avoided to maintain said worker classification. Upwork may have the same worker classification, but it saw effectiveness issues in some criteria stem from the same tools that made it effective according to other criteria. The rating system which helped it reach some criteria also held it back for other criteria.

\section{Uber}

Out of 7 influencers of effectiveness, Uber only met 3 of the criteria: privacy, reward/payment structure, and worker focus. One of the core factors in Ubers inability to use their own behavior control mechanisms effectively is their classification of workers. By not employing drivers Uber limits their ability to effectively communicate and manage their driving force.

\section{Trust}

Uber does not foster an effective environment for building trust between its drivers and users. The applications rating system is seen by drivers as an ineffective way of promoting trust, as most passengers do not understand how it works [26]. By giving the supervisorial role to riders Uber creates a form of internal team monitoring. Internal monitoring can increase trust, but this trust increase is directly tied to observed performance [15]. As observed performance is not correctly evaluated by riders, trust is not increased. 


\section{Communication}

Ubers ineffective communication stems from the platforms claim that drivers are not employees, but partners. Their use of indirect messages to drivers and other forms of soft control are done to avoid the appearance of company policy [19]. Being more direct with behavior control has potential to lead Uber to being classified as an employer. The lack of supervisors also causes a communication issue for drivers, as they are left with customer service centers or templated feedback as the only routes of communication with Uber.

\section{Worker focus/on-task}

As with other virtual platform-based work, Uber drivers have flexible work hours. They can work when they want. Uber gets workers to work when they want through push notifications, specifically ones based around surge pricing [19]. With surge pricings direct influence on worker behavior [21], Uber's use of behavior control shows itself to be an effective tool in getting workers on task.

\section{Reward/Payment structure}

Uber's use of surge pricing is an effective method to both get drivers to respond to market demand and influence drivers work when the company wants them to [19]. Uber manages to respond to an extremely dynamic market whilst separating themselves from their pricing algorithm.

\section{Feedback}

Uber's feedback tools are ineffective for the same reason its communication is ineffective, the partner status of drivers. Feedback is indirect and drivers that ask questions or request information will commonly receive templated answers [19].

\section{Worker experience}

Drivers and Uber frequently do not have the same goals, leading drivers to calculate what is beneficial for themselves and interpret the actions of the algorithms they interact with [25]. This divide leads to the extreme ineffectiveness of Ubers behavior control in worker experience. As stated previously, half of the drivers onboarded in 2013 were not using the platform a year later [19]. Losing experienced workers leads to the company filling gaps with new drivers, forcing them to spend their resources on onboarding and training.

\section{Privacy}

Uber's invasion of privacy that could potentially make for less effective behavior control tools comes from their location tracking and use of passengers as a rating system. However, the rating system is an effective tool to get drivers to build a good relationship with passengers [26]. The location tracking influences drivers to get on the road when surge pricing areas are near, even when drivers are not working.

\section{Upwork}

Out of the 6 influencers of effectiveness that Upwork could be evaluated on, only 3 were found to not meet the criteria. I find that the team application and rating system are not as effective as they could be due to issues relating to: privacy, payment structure, and trust. However, two of the three influencers whose criteria were met were done so by the team application.

\section{Trust}

The surveillance workers experience on Upwork's platform is seen by some as a positive, as it helps to establish trust with new work providers [18]. This monitoring has potential to do just that, but it does not stop when a worker is deemed to be trustworthy. Team Application will still need to be running to guarantee hourly wages, as long as the work is done through Upwork. After a period of time, this monitoring only hinders the growth of trust in a relationship [35]. Upwork does not effectively inspire a trusting relationship between workers and work providers, thereby undercutting the effectiveness of this tool.

\section{Communication}

Communication between team members in distributed worker environments can be challenging. Upwork effectively increases communication between team members through the sharing of worker diaries. All team members can access each other's work diaries after they are posted [33]. This indirect communication allows workers to better understand the workflow and more effectively approach their own tasks.

\section{Worker focus/on-task}

Upwork's Team Application is incredibly effective at making sure a worker is on task. The invasive surveillance tools it implements allow for incredibly close monitoring of workers, making being off task difficult.

\section{Reward/Payment structure}

The Team Application is a good indicator of whether or not a worker is on task, but it lacks the ability to create an effective payment structure. Since work done on the Team Application is paid for by the hour, slower workers are rewarded. High productivity workers are put at a disadvantage and even encouraged to work more slowly [18]. This issue may be inherent to all forms of hourly work, but when Upwork require an hourly reward/payment structure even when it is not the best fit for a particular project, they undermine the possibility for maximal performance.

\section{Feedback}

The feedback system used by Upwork to generate a worker's job success score is bi-directional [18]. Only the feedback from work provider to worker will be evaluated. This system is may not have much direct influence on work done by hired workers. It does however make the hiring process more efficient for work providers on the platform. By allowing a quick overview of workers success rate, Upwork created a more efficient platform.

\section{Worker experience}

Upwork's core attracting features are still the same, despite their use of behavior control mechanisms. Workers can use the platform as their primary source of income, telecommute, have flexible hours, and live around the globe [33, 18]. As there is not a clear distinction between the number of workers that found the team application to be intrusive and not intrusive [18], whether worker experience is made to be more or less effective by behavior control mechanisms cannot be determined. 


\section{Privacy}

Since monitored work is more or less a performance by the worker [24], what workers are really doing can easily be masked. The team application gathers a substantial amount of data, but it can still be worked around by workers. Hourly labour in task-based platform work can reward slower workers, more productive workers may simply circumvent the monitoring by hiding what they are actually doing. The invasion of privacy by Upwork on its laborer's is not effective.

\section{DISCUSSION}

The two most interesting things I learned during this research are: many workers are willing to accept extreme privacy invasion for a paycheck and Uber spends a lot of time, energy, and money into making some incredibly unethical tools. Upwork is surprisingly transparent when it comes to what it does with the team application. Yet many workers still use the platform as their primary source of income [18]. The paycheck and flexibility in work are more important to Upwork workers than their privacy. This is understandable, but not something that I want to see become the norm. Ubers creation of the tools Hell, Godview, and Greyball shows how far the company is willing to go to remain at the top of their industry. Even before knowing the specifics of the tool, the choices of names alone are suggestive of a lack of strong ethics. These are all tools that would require a considerable amount of resources to build, meaning Uber deemed them worthy of those resources. Companies using their mobile applications to stay ahead of the law and their competitors has potential to be a dangerous trend, if companies like Uber get away with using these tools.

Uber only met 1 of the criteria for ethical use of behavior control tools. So, In the case of Uber, does using behavior control mechanisms unethically lead to a more effective working environment? By not ethically using them, creating a more effective virtual platform with behavior control tools becomes simple. However, the answer is no. Uber increases effectiveness in only 3 influencers. These results lead us to the question, why are the tools Uber uses only somewhat effective, when ethical principles are not holding them back? The main factor holding back the effectiveness of Uber's behavior control tools is the driverpartner employment status. Feedback and communication are two influencers that would become far more effective if Uber was direct with its workers, as there would no longer be an issue with feedback looking like company policy. Goals of employed drivers would more directly align with the company, helping to decrease the divide between workers and platform, creating an environment that encourages experienced workers to stay.

Upwork met the criteria for 4 out of the 7 ethical criteria and 3 out of 6 effective criteria. The platform was able to get better overall results than Uber, mainly due to the transparency of the team application. This tool could be made to increase effectiveness in all the influencers that it was seen to decrease effectiveness by simply dulling down the applications invasiveness with time. Once it has allowed for a proper foundation of trust to be built, a new more correct payment structure can be made and the application can give the worker more privacy. If used correctly the team application has potential to be an incredibly effective tool. While Upwork may be more successful than Uber at meeting criteria for the frameworks, there are worrying trends of worker acceptance of surveillance on the platform. This acceptance is bad because workers are allowing data that is not related to the job they are doing to be gathered. By crossing the line of what is acceptable data to gather, platforms can begin to normalize the gathering of extreme amounts of data. This gives work providers the potential to monitor and influence worker behavior outside of the work place, in private areas of a workers life.

If the most popular platforms in both discussed industries ineffectively use unethical behavior control tools, will leading companies in other industries follow? Successful virtual labor platforms control behavior and invade the privacy of their workers, showing future companies that these tools are accepted by workers and do not have legal repercussions. Virtual platform workers are not the only ones experiencing invasions of their privacy, many employers for in-person jobs are beginning to use similar technology to increasing surveil their employees. Walmart recently patented technology to eavesdrop on workers private conversations [36]. Amazon has two new patents for a wristband that tracks workers every movement and alters behavior with vibrations [37]. Three Squares Market has optional microchip implanting into the hands of workers [38]. In China emotional surveillance is being attempted by the monitoring of worker brainwaves in factories, state owned enterprises, and the military [39]. Workers' rights in the case of current and future surveillance technology are incredibly important, but with so many industries using ethically questionable tools, what should be done?

There are multiple routes that lead to a future with better and more ethical use of behavior control tools, more specifically surveillance tools. The first would be laws and regulations supporting worker privacy for both in-person and telecommuting jobs. Laws protecting worker privacy are not only feasible, but already being implemented by other countries around the world. In September of 2017 the EU's human rights court ruled to limit an employer's right to monitor worker email [40]. The same court stated that the mere storing of data related to an individual's private life amounts to an interference with article 8 of the European Convention of Human Rights, which discusses the respect of privacy [41]. Austria, Britain, Finland, Luxembourg, Portugal, and Slovakia have explicitly regulated workplace privacy with domestic legislation [40].

If not laws and regulations, workers can unionize in order to protect their privacy. In the past when worker monitoring was increased due to scientific management working conditions and worker rights were improved through the labor movement by the formation of unions [42]. Unions declined in the 50's when manufacturing jobs left the country, but the dissipation of many worker protections in certain sectors and the lack of protections in new sectors [42] create a hole that new unions could fill. In order to protect worker rights and privacy the public must put its foot down and actively work towards a future were unethical technology is not used on laborers.

\section{CONCLUSION}

Behavior control tools such as awareness systems are used to increase worker effectiveness, often times crossing ethical lines, including worker privacy. By creating a framework for both ethical 
and effective use of behavior control tools I evaluated the use of said tools by Uber and Upwork. Uber failed to meet ethical standards for a majority of criteria and was also not able to reach the effective standards for a majority of the criteria. Upwork saw slightly better results reaching half of the effectiveness standards, but also did not meet a majority of the ethical criteria. Both of the platforms suffered because of their classification of workers as nonemployees and from lack of transparency in policies. Worker rights around behavior control tools can be improved in the future with the creation of new laws and regulations and through the unionization of platform and other workers.

\section{REFERENCES}

1. I. Ajunwa, K. Crawford, and J. Schultz, "Limitless Worker Surveillance," Social Science Research Network, Rochester, NY, SSRN Scholarly Paper ID 2746211, Mar. 2016.

2. R. Fitzpatrick, "CHALLENGES AND INTERVENTIONS IN MONITORING AND EVALUATING VIRTUAL TEAM PERFORMANCE," Cornell Center for Advanced Human Resource Studies,

3. G. Piccoli and B. Ives, "Trust and the Unintended Effects of Behavior Control in Virtual Teams," Management Information Systems Quarterly, vol. 27, no. 3, Sep. 2003.

4. D. Kravets, "Worker fired for disabling GPS app that tracked her 24 hours a day," Ars Technica, 11-May-2015. Available: https://arstechnica.com/tech-policy/2015/05/worker-fired-fordisabling-gps-app-that-tracked-her-24-hours-a-day/. [Accessed: 08Jun-2018].

5. K. Coomes, “The Best Ridesharing Rpps," Digital Trends, 05-Jul-2018. [Online]. Available: https://www.digitaltrends.com/mobile/best-ridesharing-apps/2/. [Accessed: 29-Jul-2018].

6. A. Muhammed, "79 Websites To Get Freelance Jobs Fast," Forbes. [Online]. Available: https://www.forbes.com/sites/abdullahimuhammed/2017/06/16/79websites-to-get-freelance-jobs-fast/. [Accessed: 29-Jul-2018].

7. Global Workplace Analytics, “-2018 Alternative Workplace Strategies Fifth Biennial Benchmarking Study," Global Workplace Analytics, 01Jul-2018. [Online].Available: http://globalworkplaceanalytics.com/telecommuting-statistics. [Accessed: 29-Jul-2018].

8. "ACM History." [Online]. Available: https://www.acm.org/aboutacm/acm-history. [Accessed: 20-June-2018].

9. "ACM Constitution." [Online]. Available: https://www.acm.org/governance/acm-constitution. [Accessed: 20June-2018].

10. "Code of Ethics," ACM Ethics [Online]. Available https://ethics.acm.org/code-of-ethics. [Accessed 20-June-2018.]

11. "What is confidentiality, integrity, and availability (CIA triad)? Definition from WhatIs.com," WhatIs.com. [Online]. Available: https://whatis.techtarget.com/definition/Confidentiality-integrity-andavailability-CIA. [Accessed: 13-Aug-2018]

12. J. Yerby, "Legal and ethical issues of employee monitoring," Online Journal of Applied Knowledge Management vol. 1, no. 2, pp. 44-55, 2013.

13. L. P. Robert, "A multi-level analysis of the impact of shared leadership in diverse virtual teams," 2013, p. 363.

14. S. C. University, "LittleBrother is watching you." [Online]. Available: https://www.scu.edu/ethics/focus-areas/business-

ethics/resources/littlebrother-is-watching-you/. [Accessed: 21-June2018].

15. L. P. Robert Jr., "Monitoring and Trust in Virtual Teams," in Proceedings of the 19th ACM Conference on Computer-Supported Cooperative Work \& Social Computing, New York, NY, USA, 2016, pp. 245-259.

16. A. R. Dennis, L. P. Robert, A. M. Curtis, S. T. Kowalczyk, and B. K. Hasty, Trust Is in the Eye of the Beholder: A Vignette Study of Postevent Behavioral Controls' Effects on Individual Trust in Virtual Teams," Information Systems Research, vol. 23, no. 2, pp. 546-558, Jun. 2012.

17. L. P. R. Jr, "Trust and Control in Virtual Teams: Unraveling the impact of Team Awareness Systems in Virtual Teams," p. 3.

18. B. Caraway, "Online labour markets: an inquiry into oDesk providers," Work Organisation, Labour \& Globalisation, vol. 4, no. 2, pp. 111-125, 2010.
19. A. Rosenblat and L. Stark, "Algorithmic Labor and Information Asymmetries: A Case Study of Uber's Drivers," International Journal of Communication, vol. 10, no. 0, p. 27, Jul. 2016.

20. J. O'Neill and D. Martin, "Relationship-Based Business Process Crowdsourcing?," in Human-Computer Interaction - INTERACT 2013, 2013, pp. 429-446.

21. M. K. Lee, D. Kusbit, E. Metsky, and L. Dabbish, "Working with Machines: The Impact of Algorithmic and Data-Driven Management on Human Workers," 2015, pp. 1603-1612.

22. E. S. Bernstein, "The Transparency Paradox: A Role for Privacy in Organizational Learning and Operational Control," Administrative Science Quarterly, vol. 57, no. 2, pp. 181-216, Jun. 2012.

23. A. O'Brien, "Uber has more work to do winning over drivers," CNNMoney, 18-Dec-2017. [Online]. Available: http://money.cnn.com/2017/12/18/technology/uber-drivers-180-daysof-change/index.html. [Accessed: 25-June-2018].

24. M. Glöss, M. McGregor, and B. Brown, "Designing for Labour: Uber and the On-Demand Mobile Workforce," in Proceedings of the 2016 CHI Conference on Human Factors in Computing Systems, New York, NY, USA, 2016, pp. 1632-1643.

25. N. F. Ma, C. W. Yuan, M. Ghafurian, and B. V. Hanrahan, "Using Stakeholder Theory to Examine Drivers' Stake in Uber," in Proceedings of the 2018 CHI Conference on Human Factors in Computing Systems, New York, NY, USA, 2018, pp. 83:1-83:12.

26. N. Raval and P. Dourish, "Standing Out from the Crowd: Emotional Labor, Body Labor, and Temporal Labor in Ridesharing," in Proceedings of the 19th ACM Conference on Computer-Supported Cooperative Work \& Social Computing, New York, NY, USA, 2016, pp. 97-107.

27. M. Murphy, "Uber's future depends on convincing a London court it has changed," Quartz, 24-Jun-2018. [Online]. Available: https://qz.com/1313249/uber-battles-in-court-for-its-london-licenseand-its-global-future/. [Accessed: 25-Jun-2018].

28. A. Pasick, "If you thought it was creepy for Uber to track you at all times, it was actually much worse," Quartz, 03-Mar-2017. [Online]. Available: https://qz.com/924459/ubers-greyball-surveillanceprogram-tracked-police-phones/. [Accessed: 25-Jun-2018]

29. M. Isaac, "How Uber Deceives the Authorities Worldwide," The New York Times, 03-Mar-2017. [Online]. Available: https://www.nytimes.com/2017/03/03/technology/uber-greyballprogram-evade-authorities.html. [Accessed: 25-Jun-2018].

30. A. Press, "Feds probe Uber's tracking of Lyft drivers," latimes.com. [Online]. Available: http://www.latimes.com/business/la-fi-uberinvestigation-lyft-20170908-story.html. [Accessed: 31-Jul-2018].

31. M. Serr, "Uber Driver Tracking and Telematics," Geotab Blog, 15-Jan2018. [Online]. Available: https://www.geotab.com/blog/uber-drivertracking/. [Accessed: 31-Jul-2018].

32. A. Gandini, I. Pais, and D. Beraldo, "Reputation and trust on online labour markets: the reputation economy of Elance," Work Organisation, Labour \& Globalisation, vol. 10, no. 1, p. 27, 2016.

33. P. Popiel, "Boundaryless' in the creative economy: assessing freelancing on Upwork," Critical Studies in Media Communication, vol. 34, no. 3, pp. 220-233, May 2017.

34. P. Davidson, "Watching over freelancers," USA Today, pp. 03-03, Sep. 2010.

35. P. Patel-Predd, "The all-seeing employer - [careers]," IEEE Spectrum, vol. 46, no. 1, pp. 23-23, Jan. 2009.

36. N. Jones, A. Vasguard, R. Taylor, and M. Jones, "Listening To The Frontend," 10-Jul-2018.

37. C. Yeginsu, "If Workers Slack Off, the Wristband Will Know. (And Amazon Has a Patent for It.)," The New York Times, 08-Feb-2018.

38. A. B. C. News, "Amazon employee wristbands spark concerns as more companies monitor workers with tech," ABC News, 10-Mar-2018. [Online]. Available: https://abcnews.go.com/US/companiestechnology-monitor-employees-sparking-privacyconcerns/story?id=53388270. [Accessed: 29-Jul-2018].

39. "These Chinese workers' brain waves are being monitored," World Economic Forum. [Online]. Available: https://www.weforum.org/agenda/2018/05/china-is-monitoringemployees-brain-waves-and-emotions-and-the-technology-boostedone-companys-profits-by-315-million/. [Accessed: 29-Jul-2018].

40. S. Chan, "European Court Limits Employers' Right to Monitor Workers' Email," The New York Times, 22-Dec-2017.

41. "Factsheet - Personal data protection," echr. 01-Jun-2018. [Online]. Available: https://www.echr.coe.int/Documents/FS_Data_ENG.pdf

42. T. Kneese, A. Rosenblat and danah boyd, "Understanding Fair Labor Practices in a Networked Age," Social Science Research Network, Rochester, NY, SSRN Scholarly Paper ID 2536619, Oct. 2014. 